\title{
Alteration of urinary sorbitol excretion in WBN-kob diabetic rats - treatment with an aldose reductase inhibitor
}

\author{
Toru Tsugawa, Rikio Shinohara ${ }^{1}$, Akio Nagasaka, Itsuko Nakano, \\ Fumiko Takeda, Minoru Nagata ${ }^{2}$, Naohisa Oda, Yoshikuni Sawai, \\ Nobuki Hayakawa, Atsushi Suzuki and Mitsuyasu Itoh
}

Department of Internal Medicine, Fujita Health University School of Medicine, Toyoake, Aichi 470-1192, Japan

${ }^{1}$ Department of Biochemistry, Fujita Health University School of Hygiene, Toyoake, Aichi 470-1192, Japan

${ }^{2}$ Department of Internal Medicine and Pharmacy, Fujita Health University School of Medicine, Toyoake, Aichi 470-1192, Japan

(Requests for offprints should be addressed to Mitsuyasu Itoh, Division of Endocrinology and Metabolism, Department of Internal Medicine, Fujita Health University School of Medicine, Toyoake, Aichi 470-1192, Japan)

\begin{abstract}
An accerelated polyol pathway in diabetes contributes to the development of diabetic complications. To elucidate diabetic nephropathy involving also renal tubular damage, we measured urinary sorbitol concentration concomitantly with urinary N-acetyl-D-glucosaminidase (NAG) excretion in WBN-kob diabetic rats.

Twenty-four-hour urinary sorbitol concentrations increased in the diabetic rats in parallel with whole blood sorbitol concentrations. An increase in 24-h urinary NAG excretion coincided with the elevated urinary sorbitol levels in the diabetic rats.
\end{abstract}

The administration of epalrestat, an aldose reductase inhibitor, reduced the increased whole blood and urinary sorbitol concentrations and urinary NAG excretion concomitantly with renal aldose reductase inhibition in the diabetic rats.

These results indicate that diabetic nephropathy involves distorted cell function of renal tubules, and that treatment with epalrestat may prevent at least the progress of the nephropathy.

Journal of Endocrinology (2004) 181, 429-435

\section{Introduction}

A number of experimental and clinical studies suggest that, in addition to glycation, activation of the polyol pathway may play an important role in the development of diabetic complications (Gabbay 1973). The polyol pathway is an alternative route of glucose metabolism which is composed of two enzyme reactions, catalyzed by aldose reductase and sorbitol dehydrogenase. Aldose reductase, the rate-limiting enzyme in this pathway, catalyzes the reduction of glucose to sorbitol. Sorbitol is subsequently converted to fructose by sorbitol dehydrogenase. It is believed that acceleration of this pathway occurs in hyperglycemic metabolism, contributing to development of diabetic complications. To estimate the glucose metabolic state of the whole body and peripheral tissues, many investigators have determined sorbitol levels in various tissues, such as the erythrocytes, peripheral nerves, the lens, the retina and renal tissues, and analyzed the correlation between sorbitol levels and diabetic complications (Malone et al. 1980, Greene et al. 1985, Naeser \& Brolin 1991, Stevens et al. 1995). Elevated levels of urinary sorbitol excretion measured by gas chromatography (Yoshii et al. 2001) or using the improved method (Nakano et al. 2003) were also observed in the diabetic patient.

Recently, many aldose reductase inhibitors have been developed and have been shown to prevent or ameliorate diabetic complications (Kador et al. 1985); thus the importance of the polyol pathway in diabetes has attracted more attention.

On the other hand, it has been reported that N-acetylD-glucosaminidase (NAG) activity in urine increased during the development of the early stages of diabetic nephropathy, and is correlated with the increase of urinary microalbumin and other parameters relevant to diabetes (UK Prospective Diabetes Study 1993, Hsiao et al. 1996, Kato et al. 1997, Yamanouchi et al. 1998, Ishii et al. 2001). Although NAG is widely distributed in various organs, it is especially concentrated in the epithelial cells of the renal proximal tubules (Price 1992). Thus, the increase in urinary NAG activity suggests that the cell injury is in the renal proximal tubules.

Taken together, these findings prompted us to evaluate diabetic renal function, measuring urinary sorbitol levels, using our improved method, and NAG excretion in Wistar-Bonn/Kobori (WBN-kob) rats, a spontaneously 
generated diabetic model, in response to treatment with an aldose reductase inhibitor.

\section{Materials and Methods}

\section{Chemicals}

Sorbitol, sodium hydroxide, zinc sulfate, ethylenediamine$\mathrm{N}, \mathrm{N}, \mathrm{N}, \mathrm{N}$-tetraacetate (EDTA) and tris (hydroxymethyl) aminomethane (Tris) were of special grade and were purchased from Wako Pure Chemicals (Osaka, Japan). B-5 ion exchange resin was purchased from Katayama Chemical Co. (Nagoya, Japan). $\mathrm{NAD}^{+}$was obtained from Oriental Yeast Co. (Tokyo, Japan). Sheep liver sorbitol dehydrogenase (SDH) was from Roche Diagnostics GmbH (Mannheim, Germany) and Pseudomonas SDH was from Kikoman Co. (Tokyo, Japan).

\section{Animals}

Seventeen male 55-week-old WBN-kob rats weighing 330-370 g were purchased from Japan SLC Inc. Lab. (Hamamatsu, Japan). Rats were housed in a temperaturecontrolled room with lights on from 0700 to $1800 \mathrm{~h}$ and were allowed a standard rat chow diet and water available ad libitum. Two weeks after receiving the rats from the Japan SLC Inc. Lab., rats with blood glucose levels over $13.9 \mathrm{mmol} / \mathrm{l}$ were used as diabetic rats. The diabetic rats were randomly divided into two groups, i.e. diabetic rats and epalrestat-treated diabetic rats. Five male age-matched Wistar rats from Japan SLC Inc. Lab. were used as controls.

Epalrestat (an aldose reductase inhibitor, donated by Ono Pharmaceutical Co., Ltd, Osaka, Japan) was administered by oral gavage once daily at a dose of $50 \mathrm{mg} / \mathrm{kg}$ body weight for 49 days. Body weights of these rats were measured weekly and 24-h urinary specimens were collected before and every ten days after the onset of diabetes.

Whole blood specimens were obtained from cardiac paracentesis. The experiments conformed to the Guidelines on the Handling and Training of Laboratory Animals in our university.

\section{Preparation of whole blood samples}

One milliliter of whole blood obtained from each group of rats was diluted with distilled water to a final volume of $6.0 \mathrm{ml}$. After the addition of $1.0 \mathrm{ml}$ of $0.475 \mathrm{~mol} / 1 \mathrm{NaOH}$, $1.0 \mathrm{ml}$ of $0.293 \mathrm{~mol} / 1 \mathrm{ZnSO}_{4}$ was added. The mixture was stirred and centrifuged at $2000 \times \boldsymbol{g}$ for $10 \mathrm{~min}$, and the supernatant was used for whole blood samples.

\section{Preparation of urine samples}

Each group of rats was placed in individual metabolic cages to collect urine for a 24-h period for the measurement of sorbitol concentrations. The rats were fed and given water during the collection of urine specimens, which were kept at $-4{ }^{\circ} \mathrm{C}$ prior to analysis.

Two milliliters of the urinary specimens were diluted with $1.0 \mathrm{ml}$ distilled water and this diluted urine specimen was applied to an Amberlite MB-3 (ORGANO Corp., Tsukuba Plant, Japan) column $(1 \times 12.5 \mathrm{~cm})$ to remove ionic substances which interfere with the assay system. Then, $20 \mathrm{ml}$ distilled water were applied to the column to elute the urine specimen. After the addition of $1.0 \mathrm{ml}$ of $0.475 \mathrm{~mol} / 1 \mathrm{NaOH}$ to $5 \mathrm{ml}$ of the eluate, $1.0 \mathrm{ml}$ of $0.293 \mathrm{~mol} / 1 \mathrm{ZnSO}_{4}$ was added, and the mixture was stirred and centrifuged at $2000 \times \boldsymbol{g}$ for $10 \mathrm{~min}$. Then, the supernatant was used for urine samples.

\section{Determination of sorbitol concentration}

Sorbitol was assayed by a fluorometric and enzymatic method as described previously (Shinohara et al. 1998b). In brief, $2.0 \mathrm{ml}$ whole blood or urine sample were mixed with $1.0 \mathrm{ml}$ of $0.15 \mathrm{~mol} / 1$ Tris $-\mathrm{HCl}$ buffer $(\mathrm{pH} 8.6$ ) containing $4.5 \mathrm{mmol} / 1 \mathrm{EDTA}, 3.0 \mathrm{mmol} / 1 \mathrm{NAD}^{+}$and $2 \mathrm{U} / \mathrm{ml} \mathrm{SDH}$. This reaction mixture was incubated at $37^{\circ} \mathrm{C}$ for $30 \mathrm{~min}$. Another $2.0 \mathrm{ml}$ of the sample, mixed with $1.0 \mathrm{ml}$ Tris $-\mathrm{HCl}$ buffer without $\mathrm{SDH}$ were also incubated as a blank. The relative fluorescence of NADH produced in the conversion of sorbitol to fructose catalyzed by SDH was measured using a JASCO spectorofluorometer FP-777 (JASCO, Tokyo, Japan), with an excitation wavelength of $366 \mathrm{~nm}$ and an emission wavelength of $452 \mathrm{~nm}$. The inter- and intra-assay coefficients of variation were 4.4 and $4.5 \%$ respectively.

\section{Measurement of urinary $N$-acetylglucosaminidase (NAG) activity}

The urinary total NAG activity was determined with a spectrophotometric assay kit using 3,3-dichlorophenyl-sulfon-phthaleinyl-NAG as a substrate (Shionogi Pharmaceutical Co. Ltd, Osaka, Japan) (Noto et al. 1983).

The mean analytical recovery of NAG in human urine was $101 \%$. The within- and between-assay coefficients of variation were about $5 \%$.

\section{Measurement of aldose reductase activity in rat kidney}

Aldose reductase activity was assayed according to the method reported previously (Shinohara et al. 1998a).

\section{Protein assay}

The protein concentration in the sample was determined using the Bio-Rad protein assay kit (Bio-Rad Lab., Hercules, CA, USA).

\section{Statistical analysis}

ANOVA and a post hoc (Bonferroni/Dunn) test or Kruskal-Wallis test were used for comparing groups; 
Table 1 Body weights and blood and urinary glucose levels in control, diabetic and Epalrestat-treated diabetic rats. Oral administration of Epalrestat at a dose of $50 \mathrm{mg} / \mathrm{kg} \mathrm{BW} /$ day was started at 57 weeks of age $(A=$ initial values at the beginning of the study) for 49 consecutive days ( $B=$ absolute values at the end of the study).

Each value is the mean \pm S.E.

\begin{tabular}{|c|c|c|c|c|c|}
\hline & \multirow[b]{2}{*}{$n$} & \multicolumn{2}{|c|}{$\begin{array}{l}\text { Body weight } \\
\text { (g) }\end{array}$} & \multirow{2}{*}{$\begin{array}{l}\text { Blood glucose } \\
(\mathrm{mmol} / \mathrm{dl}) \\
\text { B }\end{array}$} & \multirow{2}{*}{$\begin{array}{l}\text { Urinary glucose } \\
(\mathrm{mmol} / \mathrm{mg} \cdot \text { creatinine }) \\
\text { B }\end{array}$} \\
\hline & & A & $\mathrm{B}$ & & \\
\hline \multicolumn{6}{|l|}{ Group } \\
\hline Control & 5 & $339 \pm 9$ & $634 \pm 24$ & $0.63 \pm 0.03$ & $0.007 \pm 0.003$ \\
\hline Diabetic & 7 & $330 \pm 8$ & $312 \pm 11^{*}$ & $1 \cdot 78 \pm 0 \cdot 10^{*}$ & $7 \cdot 809 \pm 1 \cdot 172^{*}$ \\
\hline Epalrestat-treated diabetic & 10 & $347 \pm 9$ & $331 \pm 11^{*}$ & $1 \cdot 71 \pm 0 \cdot 11^{*}$ & $7 \cdot 876 \pm 0.944^{*}$ \\
\hline
\end{tabular}

${ }^{*} P<0 \cdot 05$, significantly different from the control group.

$P<0.05$ was considered statistically significant. Linear relations between variables were evaluated by regression analysis.

\section{Results}

The changes in body weight and fasting blood glucose levels for all rat groups are shown in Table 1. In the diabetic rats, body weights were significantly decreased and fasting blood glucose levels were increased compared with control rats. The administration of epalrestat had no effect on the body weight or fasting blood glucose levels in the diabetic rats.

Table 2 shows whole blood sorbitol levels per $\mathrm{g} \cdot \mathrm{Hb}$ ( $\mathrm{Hb}$ concentrations were similar in all groups) and urinary sorbitol and NAG excretion (similar results were obtained compared with those per day or per creatinine) in each group.

Diabetic rats revealed significantly higher levels of whole blood sorbitol than control rats. In epalrestat-treated diabetic rats, whole blood sorbitol concentrations tended to be suppressed compared with non-treated diabetic rats.

In diabetic rats, 24-h urinary sorbitol excretion, expressed as the amount of the increase at the end of the experiment, was significantly increased compared with that of control rats. In epalrestat-treated diabetic rats, 24-h sorbitol excretion was significantly suppressed $(0 \cdot 824 \pm$ $0.135 \mu \mathrm{mol} / \mathrm{mg}$ creatinine) compared with diabetic rats.

Figure 1 shows a significant positive correlation between whole blood sorbitol concentration and 24-h urinary sorbitol excretion in control, diabetic and epalrestat-treated rats. Twenty-four-hour urinary sorbitol concentrations also correlated with fasting blood glucose and urinary glucose levels in control rats or in diabetic and epalrestat-treated rats (Figs 2 and 3).

To investigate whether 24-h urinary sorbitol excretion plays a role in diabetic nephropathy, we measured 24-h urinary NAG activity, which is a measure of diabetic renal function, and compared it with the change in 24-h urinary sorbitol excretion in these rats. Urinary NAG activity, expressed as the amount of the increase at the end of the experiment, is shown in Table 2. The diabetic rats showed a significant increase in urinary NAG activity in comparison with control rats. However, in epalrestat-treated diabetic rats, the increase in urinary NAG activity was significantly suppressed compared with that of nonetreated diabetic rats.

Figure 4 shows a significant positive correlation between the 24-h urinary NAG activity and the 24-h sorbitol excretion in control rats or in diabetic and epalrestat-treated rats.

Table 2 Changes in whole blood sorbitol concentration (absolute values at the end of the study) and 24-h urinary sorbitol and NAG excretion (values are the difference between the initial value and that at the end of the study) in control, diabetic and Epalrestat-treated diabetic rats. Each value is the mean \pm S.E.

\begin{tabular}{|c|c|c|c|c|}
\hline & $n$ & $\begin{array}{l}\text { Whole blood } \\
\text { sorbitol level } \\
(\mu \mathrm{mol} / \mathrm{g} \cdot \mathrm{Hb})\end{array}$ & $\begin{array}{l}\text { Urinary sorbitol level } \\
(\mu \mathrm{mol} / \mathrm{mg} \cdot \text { creatinine })\end{array}$ & $\begin{array}{l}\text { Urinary NAG excretion } \\
\left(\mathrm{mU} / \mathrm{mg} \cdot{ }^{\circ} \text { creatinine }\right)\end{array}$ \\
\hline \multicolumn{5}{|l|}{ Group } \\
\hline Control & 5 & $0 \cdot 55 \pm 0 \cdot 80$ & $0 \cdot 196 \pm 0.031$ & $10 \cdot 8 \pm 1 \cdot 9$ \\
\hline Diabetic & 7 & $2 \cdot 41 \pm 0 \cdot 41^{*}$ & $1 \cdot 192 \pm 0.072^{* *}$ & $58 \cdot 3 \pm 7 \cdot 8^{*}$ \\
\hline Epalrestat-treated diabetic & 10 & $2 \cdot 11 \pm 0 \cdot 18^{*}$ & $0 \cdot 824 \pm 0.135^{* * \dagger}$ & $35 \cdot 8 \pm 5 \cdot 7^{* \dagger}$ \\
\hline
\end{tabular}

${ }^{*} P<0 \cdot 001,{ }^{*} P<0 \cdot 01$ compared with the control group; ${ }^{\dagger} P<0 \cdot 05$ compared with the diabetic group. 


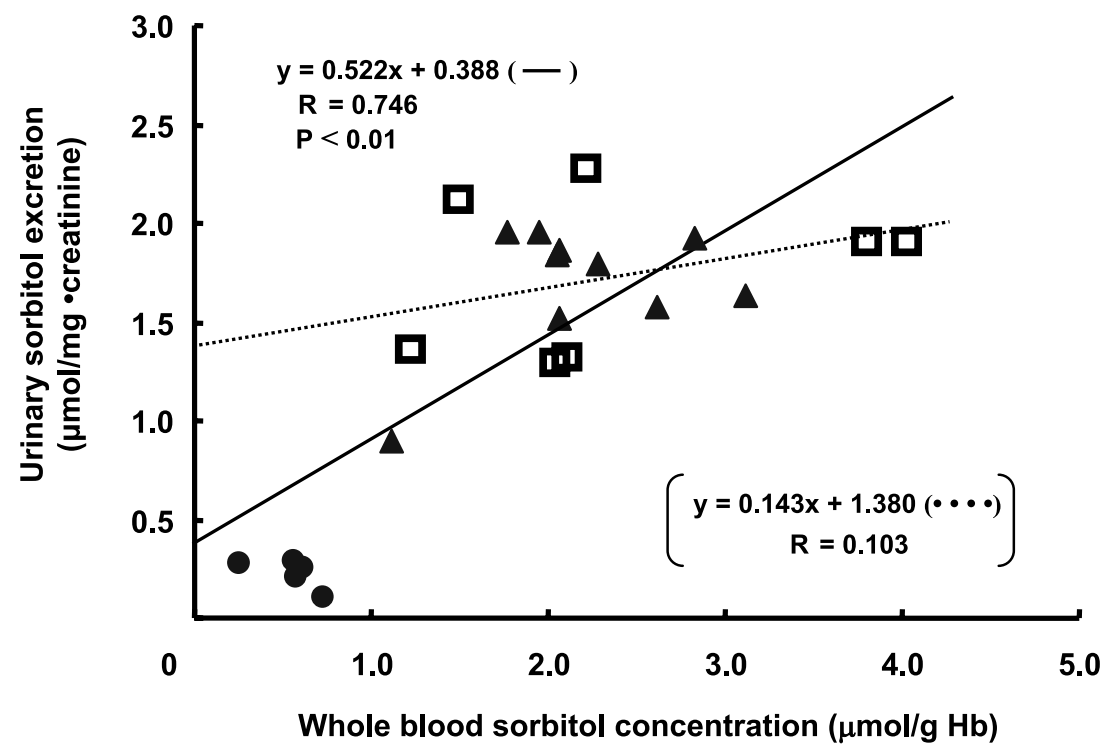

Figure 1 Correlation between whole blood sorbitol and urinary sorbitol concentrations in control $(\boldsymbol{O})$, diabetic $(\square)$ and epalrestat-treated diabetic $(\boldsymbol{\Delta})$ rats. The solid line represents the combined control and diabetic rats. The dotted line represents the diabetic (epalrestat-treated and untreated) rats.

We also assessed the accelerated polyol pathway in the diabetic kidney by measuring aldose reductase (AR) activity and sorbitol content in all groups (Table 3).

In the diabetic state, AR activity and sorbitol content of the kidney were significantly increased compared with those of control rats. In diabetic rats treated with epalrestat, the AR activity was significantly suppressed compared with that of none-treated diabetic rats. However, the sorbitol concentration tended to be reduced compared with that of diabetic rats, but was not statistically significant.

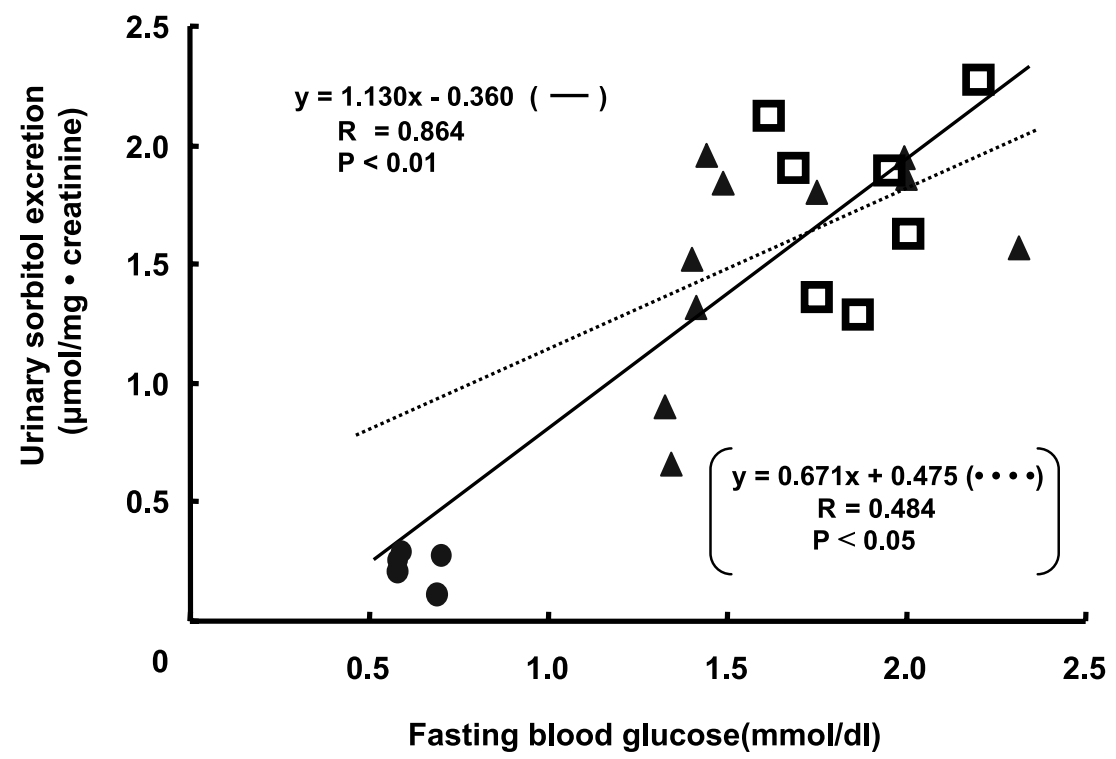

Figure 2 Correlation between urinary sorbitol excretion and fasting blood glucose levels in control ( $)$, diabetic $(\square)$ and epalrestat-treated diabetic $(\boldsymbol{\Delta})$ rats. The solid line represents the combined control and diabetic rats. The dotted line represents the diabetic (epalrestat-treated and untreated) rats. 


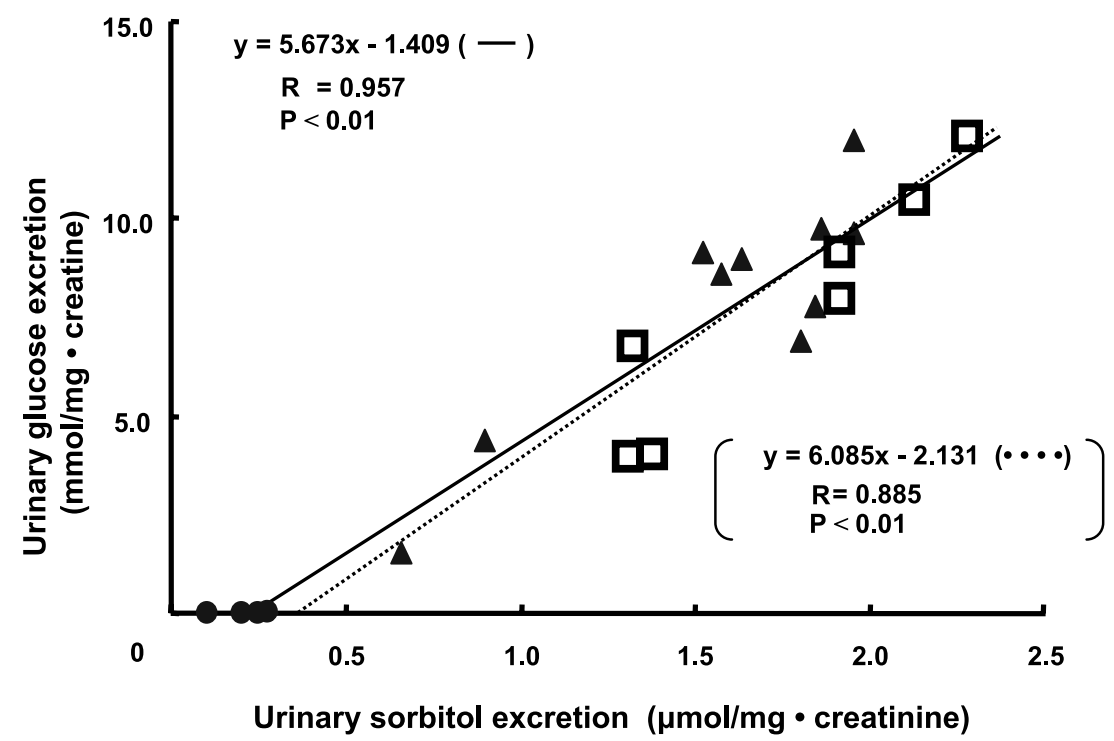

Figure 3 Correlation between urinary sorbitol excretion and urinary glucose excretion in control ( $)$, diabetic $(\square)$ and epalrestat-treated diabetic ( $\mathbf{\Delta})$ rats. The solid line represents the combined control and diabetic rats. The dotted line represents the diabetic (epalrestat-treated and untreated) rats.

\section{Discussion}

It is of crucial importance in diabetic treatment to prevent diabetic complications, such as nephropathy, as well as to assess long-term glycemic control. Although various factors are considered to be involved in the development of diabetic complications, the activation of the polyol metabolic pathway caused by hyperglycemia has a critical role. Therefore, various investigators have evaluated the polyol pathway in various diabetic organs to predict the development of diabetic complications (Gabbay 1975). For example, sorbitol concentrations in erythrocytes, as an

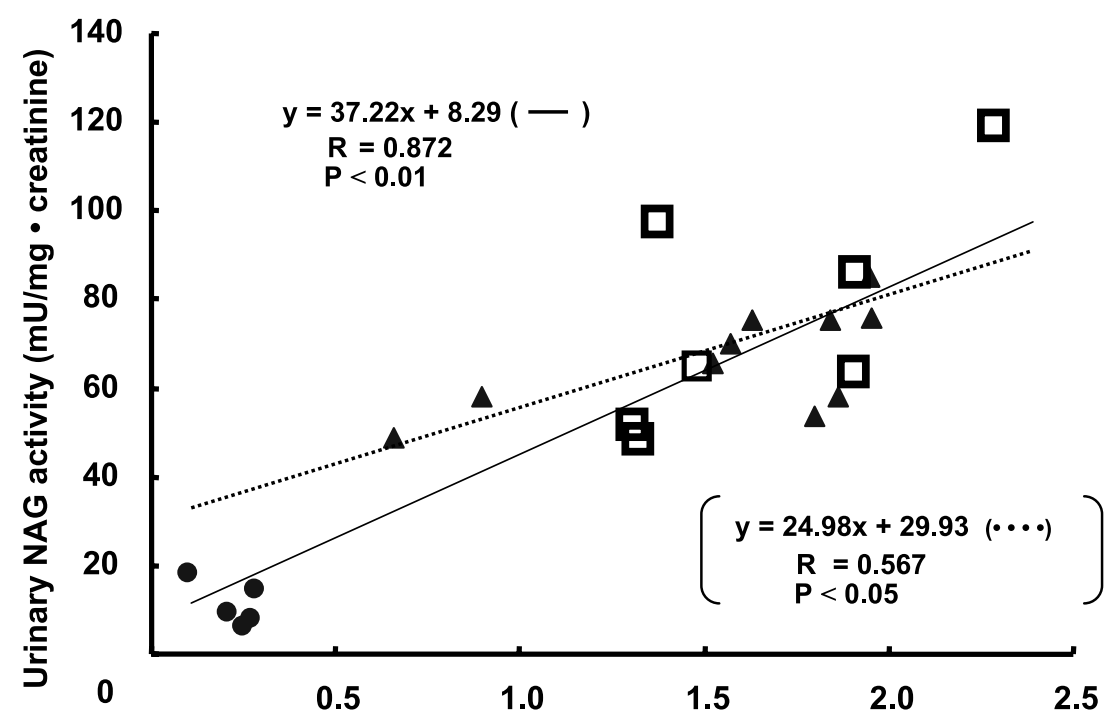

Urinary sorbitol excretion ( $\mu \mathrm{mol} / \mathrm{mg} \cdot$ creatinine)

Figure 4 Correlation between urinary sorbitol excretion and urinary NAG activities in control $(\bullet)$, diabetic $(\square)$ and epalrestat-treated diabetic $(\boldsymbol{\Delta})$ rats. The solid line represents the combined control and diabetic rats. The dotted line represents the diabetic (epalrestat-treated and untreated) rats. 
Table 3 Renal aldose reductase (AR) activity and sorbitol concentration in control, diabetic and Epalrestat-treated diabetic rats. Each value is the mean \pm S.E. and is the absolute value at the end of the study

\begin{tabular}{|c|c|c|c|}
\hline & $n$ & $\begin{array}{l}\text { AR activity } \\
(\mathrm{mU} / \mathrm{mg} \text { protein })\end{array}$ & $\begin{array}{l}\text { Sorbitol concentration } \\
\text { (nmol/mg protein) }\end{array}$ \\
\hline \multicolumn{4}{|l|}{ Group } \\
\hline Control & 5 & $816 \pm 8$ & $2 \cdot 98 \pm 0 \cdot 15$ \\
\hline Diabetic & 7 & $969 \pm 10^{*}$ & $5 \cdot 83 \pm 0 \cdot 55^{*}$ \\
\hline Epalrestat-treated diabetic & 10 & $911 \pm 9^{* \dagger}$ & $5 \cdot 09 \pm 0 \cdot 23^{*}$ \\
\hline
\end{tabular}

intermediate metabolite of glucose metabolism, have been shown to correlate with the amount of sorbitol in nerve tissue and with retinopathy (Clements 1979, Greene 1983, Naeser \& Brolin 1991). Several hypotheses explaining how the accelerated polyol pathway relates to the development of diabetic complications are proposed as follows: depletion of myo-inositol, resulting in suppression of phosphoinositide turnover and subsequent metabolic abnormalities (Greene \& Lattimer 1983), decreased availability of NADPH (Lee et al. 1985), a cascade of metabolic imbalances initiated by an increased cytosolic ratio of free $\mathrm{NADH} / \mathrm{NAD}^{+}$resulting from increased oxidation of sorbitol to fructose (Williamson et al. 1993), and osmotic stress due to accumulation of intracellular sorbitol (Wick \& Drury 1951). In addition to these hypotheses, accumulated evidence suggests that glycation and oxidative stress may have an interaction with the polyol pathway (Giugliano et al. 1996, Hamada et al. 1996).

We have previously reported an improved fluorometric and enzymatic method for measuring urinary sorbitol concentrations, which showed good sensitivity and reproducibility (Nakano et al. 2003) and confirmed that urinary sorbitol excretion and whole blood sorbitol levels in diabetic patients were significantly higher than those in nondiabetic controls, and that the difference was more significant in urine than in whole blood (Nakano et al. 2003). In the present study, we measured urinary sorbitol and NAG excretion as well as whole blood sorbitol concentration, and evaluated their correlation with AR activity in spontaneously generated diabetic WBN-kob rats. Both urinary sorbitol excretion and whole blood sorbitol levels increased in the diabetic state and were significantly correlated. Urinary sorbitol excretion also significantly correlated with fasting blood glucose and urinary glucose levels. Treatment with epalrestat significantly suppressed the increased urinary sorbitol excretion in the diabetic rats, in concordance with whole blood sorbitol concentration (Hotta 1995, Hayashi et al. 1998). Therefore, it is thought that urinary sorbitol excretion reflects the activated polyol pathway induced by hyperglycemia in various organs, consistent with our previous report using streptozotocin-induced diabetic rats
(Shinohara et al. 1998a) and as the polyol pathway exists in mesangial cells of rat glomeruli and may have some role in the development of mesangial cell dysfunction of streptozotocin-induced diabetic rats (Kikkawa et al. 1987), the measurement of urinary sorbitol levels may be a sensitive indicator of the control of the diabetic nephropathy.

We also demonstrated that there was good correlation between urinary sorbitol excretion and urinary NAG activity, which would be anticipated as an indicator of renal proximal tubular function. This glycolytic enzyme, NAG, which catalyzes the change of N-acetyl-Dglucosaminide into $\mathrm{N}$-acetyl-D-glucosamine exists within the lysozome in the cell and consists of two major isozyme forms, A and B (Price 1992). Most of the urine from patients with renal glomerular and tubular lesions showed significant increases in values or percentages $(20-30 \%)$ of NAG isozyme B (Numata et al. 1997). In diabetic patients total high urinary NAG activity might reflect lysosomal dysfunction of both glomerular and proximal tubular epithelial cells (Morita et al. 1991). The proportion of NAG isozyme B was elevated in the urine from diabetic patients when compared with normal individuals (Severini et al. 1988) and NAG isozyme B concentration in the spot urine specimens correlated well with total NAG activity (Itoh et al. 1994), probably because the molecular size of isozyme A normally prevents its passage through the glomerulus.

Although high NAG isozyme B levels were noted in urine collected from normal males who had ejaculated semen (Itoh et al. 1994), in our study each rat was kept separate in a cage to avoid copulation, and unexpectedly high values of NAG activity were excluded from the data.

Thus, the increase in urinary NAG activity in our diabetic rats may imply that diabetic nephropathy involves damage to the cells and cell function of renal tubules.

Moreover, these distorted metabolic parameters in the diabetic condition were improved by the administration of an AR inhibitor, suggesting that this treatment may be beneficial for preventing the progress of diabetic microangiopathy. 


\section{Acknowledgements}

The authors thank Ms $\mathrm{N}$ Takekawa for preparing the manuscript.

\section{Funding}

This funding was supported by a grant from Fujita Health University.

\section{References}

Clements RS Jr 1979 Diabetic neuropathy - new concepts of its etiology. Diabetes 28 604-611.

Gabbay KH 1973 The sorbitol pathway and the complications of diabetes. New England Journal of Medicine 288 831-836.

Gabbay KH 1975 Hyperglycemia, polyol metabolism, and complications of diabetes mellitus. Annual Review of Medicine $\mathbf{2 6}$ 521-536.

Giugliano D, Ceriello A \& Paolisso G 1996 Oxidative stress and diabetic vascular complications. Diabetes Care 19 257-267.

Greene DA 1983 Metabolic abnormalities in diabetic peripheral nerve: relation to impaired function. Metabolism 32 (Suppl 1) 118-123.

Greene DA \& Lattimer SA 1983 Impaired rat sciatic nerve sodium-potassium adenosine triphosphatase in acute streptozocin diabetes and its correction by dietary myo-inositol supplementation. Journal of Clinical Investigation 72 1058-1063.

Greene DA, Lattimer S, Ulbrecht J \& Carroll P 1985 Glucose-induced alterations in nerve metabolism - current perspective on the pathogenesis of diabetic neuropathy and future directions for research and therapy. Diabetes Care 8 290-299.

Hamada Y, Araki N, Koh N, Nakamura J, Horiuchi S \& Hotta N 1996 Rapid formation of advanced glycation end products by intermediate metabolites of glycolytic pathway and polyol pathway. Biochemical and Biophysical Research Communications 228 539-543.

Hayashi R, Hayakawa N, Makino M, Nagata M, Kakizawa H, Uchimura K, Hamada M, Aono T, Fujita T, Shinohara R et al. 1998 Change in erythrocyte sorbitol concentrations measured using an improved assay system in patients with diabetic complications and treated with aldose reductase inhibitor. Diabetes Care $\mathbf{2 1}$ 672-673.

Hotta N 1995 New approaches for treatment in diabetes: aldose reductase inhibitors. Biochemical Pharmacology 5 232-243.

Hsiao PH, Tsai WS, Tsai WY, Lee JS, Tsau YK \& Chen CH 1996 Urinary N-acetyl-beta-D-glucosaminidase activity in children with insulin-dependent diabetes mellitus. American Journal of Nephrology $16300-303$.

Ishii N, Ikenaga H, Ogawa Z, Aoki Y, Saruta T \& Suga T 2001 Effects of renal sorbitol accumulation on urinary excretion of enzymes in hyperglycaemic rats. Annals of Clinical Biochemistry 38 391-398.

Itoh Y, Numata Y, Morita A, Asano Y \& Kawai T 1994 Varied value of urinary $\mathrm{N}$-acetyl-beta-D-glucosaminidase isoenzyme B in males of reproductive age. Kidney International - Supplement 47 S38-S42.

Kador PF, Robison WG Jr \& Kinoshita JH 1985 The pharmacology of aldose reductase inhibitors. Annual Review of Pharmacology and Toxicology 25 691-714.

Kato H, Takashima T, Kishikawa H, Emura S \& Ohmori K 1997 The significance of urinary $\mathrm{N}$-acetyl-beta-D-glucosaminidase for predicting early stage diabetic nephropathy. International Journal of Clinical Practice $\mathbf{5 1}$ 489-490.

Kikkawa R, Umemura K, Haneda M, Arimura T, Ebata K \& Shigeta Y 1987 Evidence for existence of polyol pathway in cultured rat mesangial cells. Diabetes 36 240-243.
Lee SM, Schade SZ \& Doughty CC 1985 Aldose reductase, NADPH and $\mathrm{NADP}^{+}$in normal, galactose-fed and diabetic rat lens. Biochimica et Biophysica Acta 841 247-253.

Malone JI, Knox G, Benford S \& Tedesco TA 1980 Red cell sorbitol: an indicator of diabetic control. Diabetes 29 861-864.

Morita E, Kaizu K, Uriu K, Hashimoto O, Komine N \& Eto S 1991 Clinical significance of urinary enzymes in diabetic nephropathy. Journal of Diabetes and its Complications 5 158-159.

Naeser P \& Brolin SE 1991 Influence of glucose, fructose and aldose reductase inhibition on retinal sorbitol metabolism. Acta Ophthalmologica 69 591-595.

Nakano I, Tsugawa T, Shinohara R, Watanabe F, Fujita T, Nagata M, Kato T, Himeno Y, Kobayashi T, Fujiwara K et al. 2003 Urinary sorbitol measurement and the effect of an aldose reductase inhibitor on its concentration in the diabetic state. Journal of Diabetes and its Complications 17 337-342.

Noto A, Ogawa Y, Mori S, Yoshioka M, Kitakaze T, Hori T, Nakamura M \& Miyake T 1983 Simple, rapid spectrophotometry of urinary $\mathrm{N}$-acetyl-beta-D-glucosaminidase, with use of a new chromogenic substrate. Clinical Chemistry 29 1713-1716.

Numata Y, Morita A, Kosugi Y, Shibata K, Takeuchi N \& Uchida K 1997 New sandwich ELISA for human urinary $\mathrm{N}$-acetyl-beta-D-glucosaminidase isoenzyme B as a useful clinical test. Clinical Chemistry 43 569-574.

Price RG 1992 Measurement of N-acetyl-beta-glucosaminidase and its isoenzymes in urine - methods and clinical applications. European Journal of Clinical Chemistry and Clinical Biochemistry 30 693-705.

Severini G, Aliberti LM \& Di Girolamo M 1988

$\mathrm{N}$-acetyl-beta-glucosaminidase isoenzymes in serum and urine of patients with diabetes mellitus. Clinical Chemistry 34 2430-2432.

Shinohara R, Mano T, Nagasaka A, Sawai Y, Uchimura K, Hayashi R, Hayakawa N, Nagata M, Makino M, Kakizawa H et al. $1998 a$ Effects of thyroid hormone on the sorbitol pathway in streptozotocin-induced diabetic rats. Biochimica et Biophysica Acta 1425 577-586.

Shinohara R, Ohta Y, Yamauchi M \& Ishiguro I 1998b Improved fluorometric enzymatic sorbitol assay in human blood. Clinica Chimica Acta 273 171-184.

Stevens MJ, Feldman EL \& Greene DA 1995 The aetiology of diabetic neuropathy: the combined roles of metabolic and vascular defects. Diabetic Medicine 12 566-579.

UK Prospective Diabetes Study (UKPDS) 1993 IX: Relationships of urinary albumin and $\mathrm{N}$-acetylglucosaminidase to glycaemia and hypertension at diagnosis of type 2 (non-insulin-dependent) diabetes mellitus and after 3 months diet therapy. Diabetologia 36 835-842.

Wick AN \& Drury DR 1951 Action of insulin on the permeability of cells to sorbitol. American Journal of Physiology 166 421-423.

Williamson JR, Chang K, Frangos M, Hasan KS, Ido Y, Kawamura T, Nyengaard JR, van den Enden M, Kilo C \& Tilton RG 1993 Hyperglycemic pseudohypoxia and diabetic complications. Diabetes 42 801-813

Yamanouchi T, Kawasaki T, Yoshimura T, Inoue T, Koshibu E, Ogata N, Funato H, Akaoka I \& Miyashita H 1998 Relationship between serum 1,5-anhydroglucitol and urinary excretion of $\mathrm{N}$-acetylglucosaminidase and albumin determined at onset of NIDDM with 3-year follow-up. Diabetes Care 21 619-624.

Yoshii H, Uchino H, Ohmura C, Watanabe K, Tanaka Y \& Kawamori R 2001 Clinical usefulness of measuring urinary polyol excretion by gas-chromatography/mass-spectrometry in type 2 diabetes to assess polyol pathway activity. Diabetes Research and Clinical Practice 51 115-123.

Received in final form 27 February 2004 Accepted 3 March 2004 